\title{
A Study in Gold: Top Romanian Scholarly Journals and Their Open Access Policies
}

\author{
Robert Coravu \\ Lecturer, $\mathrm{PhD}$ \\ University of Bucharest \\ E-mail robert.coravu@litere.unibuc.ro \\ Mihai Constantinescu \\ $\mathrm{PhDc}$ \\ University of Bucharest \\ E-mail mihai.constantinescu@drd.unibuc.ro
}

This study aims to offer a global image of the top Romanian Open Access journals. After the identification of the Romanian journals included in the most widely-used bibliometric databases (Web of Science and Scopus), some characteristics, such as their inclusion in $D O A J$ and/or ROAD, the use of Open Access licenses and the existence of processing/ submission charges are analysed. The conclusions of this study offer a perspective on the Open Access movement and its influence on Romanian scientific publishers.

Keywords: open access; scholarly journals; bibliometric databases; Romania

\section{Introduction}

\subsection{The Romanian approach to Open Science and Open Access}

In Romania, at governmental level, Open Science and Open Access (O.A.) issues have begun to spark interest over the last decade, due to the growing concerns of the EU institutions on this topic.

The National Strategy for Research, Development and Innovation 2014-2020 (Guvernul României 2014) includes as a priority, in the subchapter Access to knowledge, the obligation to ensure and support open access by facilitating the access to information for the academic institutions and by stimulating Gold O.A. publishing for researche financed through public funds.

In a recent document, Partnership for Open Government: the National Action Plan 2018-2020, in the chapter dedicated to open data, the adoption of a national strategy regarding the open access to the research output is stipulated (Guvernul României 2018).

In the Romanian scientific landscape, one can notice a similar trend. In April 2012, the Romanian Academy signed the declaration Open Science for the 21st century as member of All European Academies (ALLEA), where it is stated, among other things, that the publications "should be made openly available online, as soon and as freely as possible, as should also educational resources and software resulting from publicly funded research" (ALLEA - All European Academies 2012).

\subsection{The landscape of the Romanian scientific journals}

After 1989, the number of Romanian academic journal has increased. Unfortunately, their exact situation is difficult to know because there is no institution that keeps track of all journals.

In 2005, about 600 journals signed up to be evaluated by the National Council of Scientific

Revista Română de Biblioteconomie şi Ştiința Informării = Romanian Journal of Library and Information Science ISSN 2559-5490, ISSN-L 1841-1940 • Volume 14 Issue 42018 pp. 104-112 https://doi.org/10.26660/rrbsi.2018.14.4.104

This work is licensed under a Creative Commons Attribution-NonCommercial-NoDerivatives 4.0 International License 
Research in Higher Education; only $81 \%$ of them fullfiled the minimum criteria to be indexed in one of the four categories used for this purpose (Grosu 2005, p. 4). Another classification of Romanian journals (from 2011) found 58 ISI indexed journals (ranked in the top category) and 418 other scientific journals ranked in the second and third tier (Dumitrescu 2012, p. 185). Till now, this was the last attempt of classification of all the Romanian scientific journals. The last evaluation of Romanian journals took place during 2012 but included only journals in Arts and Humanities (UEFISCDI 2018).

Studies of Romanian journals have found that these journals tend to have a high proportion of selfcitations (Dumitrescu 2012; Robu et al 2001) and that most of the Romanian journals that are called scientific do not actually serve science, but are actually scientific popularization journals (Florian \& Florian 2006).

However, the number of Romanian scholarly journals indexed in international scientific databases increased significantly in recent years. Regarding the Romanian journals indexed in Web of Science, for example, we witnessed an important evolution, from 8 journals in 2005 (Florian \& Florian 2006) to 56 at the moment of our study was conducted (April, 2018). At the same time, following the global trend, the Open Access movement started making an impact amongst the Romanian scholarly journals. Our study seeks to correlate these two tendencies and to establish the extent to which top Romanian journals - by this meaning those whose quality has been validated through indexing in Scopus and/or Web of Science - have adopted O.A. policies in order to facilitate a wider international visibility and accessibility for Romanian research. Our main objective was a descriptive one - to collect and interpret data regarding the O.A/non-O.A. status of these Romanian journals - part of the international scientific flow.

Although Open Access is a hot topic in the research and academic community, country-wide studies regarding the O.A. publishing environment are infrequent. Most studies focus either on a specific aspect of O.A. publishing, such as hybrid journals (Laakso \& Bjork 2016), APCs (Solomon \& Bjork 2012), gold vs. green O.A. (Gargouri et al 2012) or on a different set of journals (Laakso \& Bjork 2012). Studies regarding the Romanian O.A. environment are sparse and, to the best of our knowledge, there is no country-wide study that analyzes the policies of the O.A. journals, although there are studies regarding O.A. policies (Landoy et al. 2016).

\section{Methodology}

This paper focuses only on Romanian journals that are indexed in Web of Science (WoS) and/or Scopus. The data we used was gathered in March-April, 2018.

The list of Web of Science journals has been extracted from the Web of Science Master Journal List. It only includes journals from the three main indexes (Science Citation Index, Social Sciences Citation Index, Arts and Humanities Citation Index).

The list of Scopus indexed journals has been obtained from the Scopus website and only includes active journals that have Publisher's country specified as Romania.

After obtaining the initial list of journals - designated as Group 1 (G1) - we proceeded with the identification of those that offer Open Access. We accomplished this by checking each journal's website as well as the Directory of Open Access Journals (DOAJ) and the Directory of Open Access Scholarly Resources (ROAD) databases. Only journals that are currently Open Access have been included in the final list, designated as Group 2 (G2).

When identifying O.A. journals, we chose to include all journals that offered unrestricted access to the published materials. While some O.A. definitions, such as that from the Budapest Open Access Initiative (BOAI) or the Public Library of Science (PLOS) consider O.A. as both unrestricted access and use (distribution, derivative works etc.), we choose to include all journals that offered free access to published materials in order to get the biggest possible picture. 
This study focuses on obtaining information regarding aspects of O.A. publishing (use of O.A. licenses, publishing charges, O.A. policies) as well as general aspects regarding scientific publishing (type of peer-review). The data regarding these aspects has been gathered from the journals' websites and double-checked in the DOAJ and ROAD (where available). In cases where we could only find data regarding certain aspects on one of the platforms (journal website or DOAJ/ROAD) we used that information. Situations where information from two different sources where in contradiction have been analysed on a case by case basis in order to ensure that we obtained the latest available data.

While Scopus, Web of Science and DOAJ indexing is well-known, ROAD is a relatively new initiative developed by the ISSN International Centre with the support of UNESCO, aiming to provide information regarding O.A. journals. This information is gathered from the international ISSN Network and several databases (ISSN-INTERNATIONAL CENTRE 2017?).

\section{Results}

The first important finding of our study was the number of top Romanian journals whose content is freely available: from a total of 167 journals indexed in Scopus and/or WoS (G1), 144 journals $(86 \%)$ are O.A. $(\mathrm{G} 2)$.

However, we must underline that only 69 of G2 journals (48\%) have explicit O.A. policies and/or use a Creative Commons licence to point out how their content can be used (see 3.2 for details). The majority of journals have no explicit O.A. policies, but we included them in our research because their content meets the definition given by Piwowar et al. (2018) for Bronze O.A.: "articles made free-to-read on the publisher website, without an explicit Open license".

The percentage of O.A. journals from the total of Romanian journals indexed in WoS, respectively in Scopus is over $80 \%$ (see Figure 1). As even WoS-indexed journals are mostly O.A. now, we can conclude that we have a strong commitment towards free access to scientific literature in the top tier of Romanian journals.

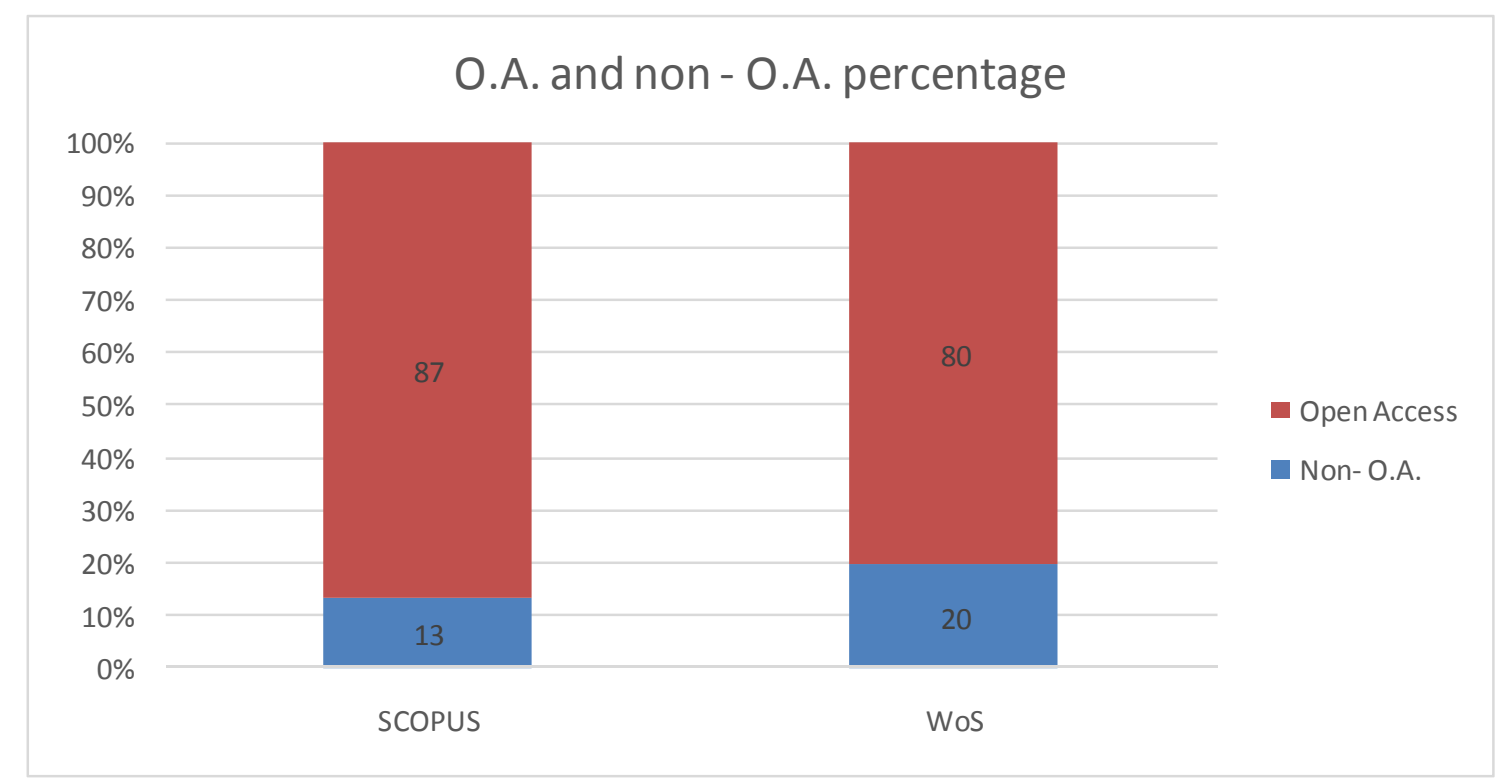

Figure 1. The percentage of O.A. and non-O.A. Romanian journals indexed in Web of Science or Scopus 


\subsection{Indexing status of identified O.A. journals}

141 journals from G2 are indexed in Scopus, 62 in ROAD, 45 in WoS and 43 in DOAJ (see Figure 2). Although ROAD was launched in the end of 2013 (while DOAJ was launched in 2003), we have more ROAD indexed journals that DOAJ. This is probably a result of the fact that DOAJ indexing requires journals to submit an application, while ROAD indexing is done by the national ISSN centres.

No. of journals

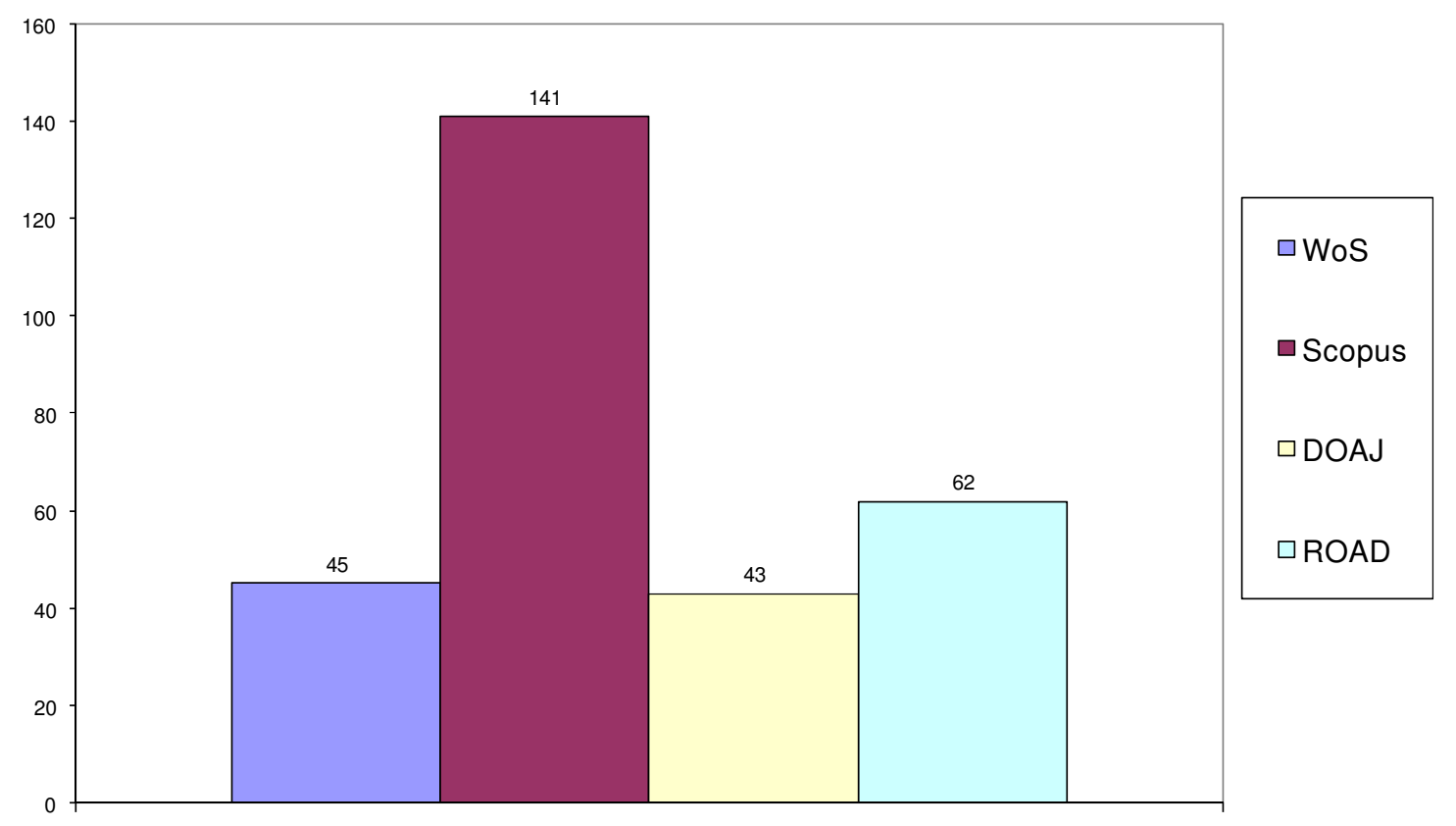

Figure 2. Indexing status of G2 journals

Most of the G2 journals, 46 (32\%), are only indexed in Scopus, 24 (17\%) are indexed in Scopus, DOAJ and ROAD and $22(15 \%)$ are indexed both in WoS and Scopus. Only 7 journals (5\%) are indexed in all the investigated databases (WoS, Scopus, DOAJ, and ROAD) (see Fig. 3). 68 of G2 journals (about $48 \%$ of the total) are not indexed in DOAJ or ROAD. This tells us that, although we have a high percentage of O.A. journals, almost half of them are not accessible through the most common O.A. directories.

\subsection{O.A. licences}

As previously shown, the majority of G2 journals provides Bronze O.A., i.e. they provide free access to their content without making any kind of reference to an Open Access policy. Only 68 journals of G2 use explicit O.A. licences. Most of them are licences formulated by the publishers in their own terms (28 journals), while the rest are different types of Creative Commons licences, varying from the most open (CC BY - 18 journals) to the most restrictive (CC BY NC ND - 14 journals) (see Fig. 4). 


\section{No. of journals}

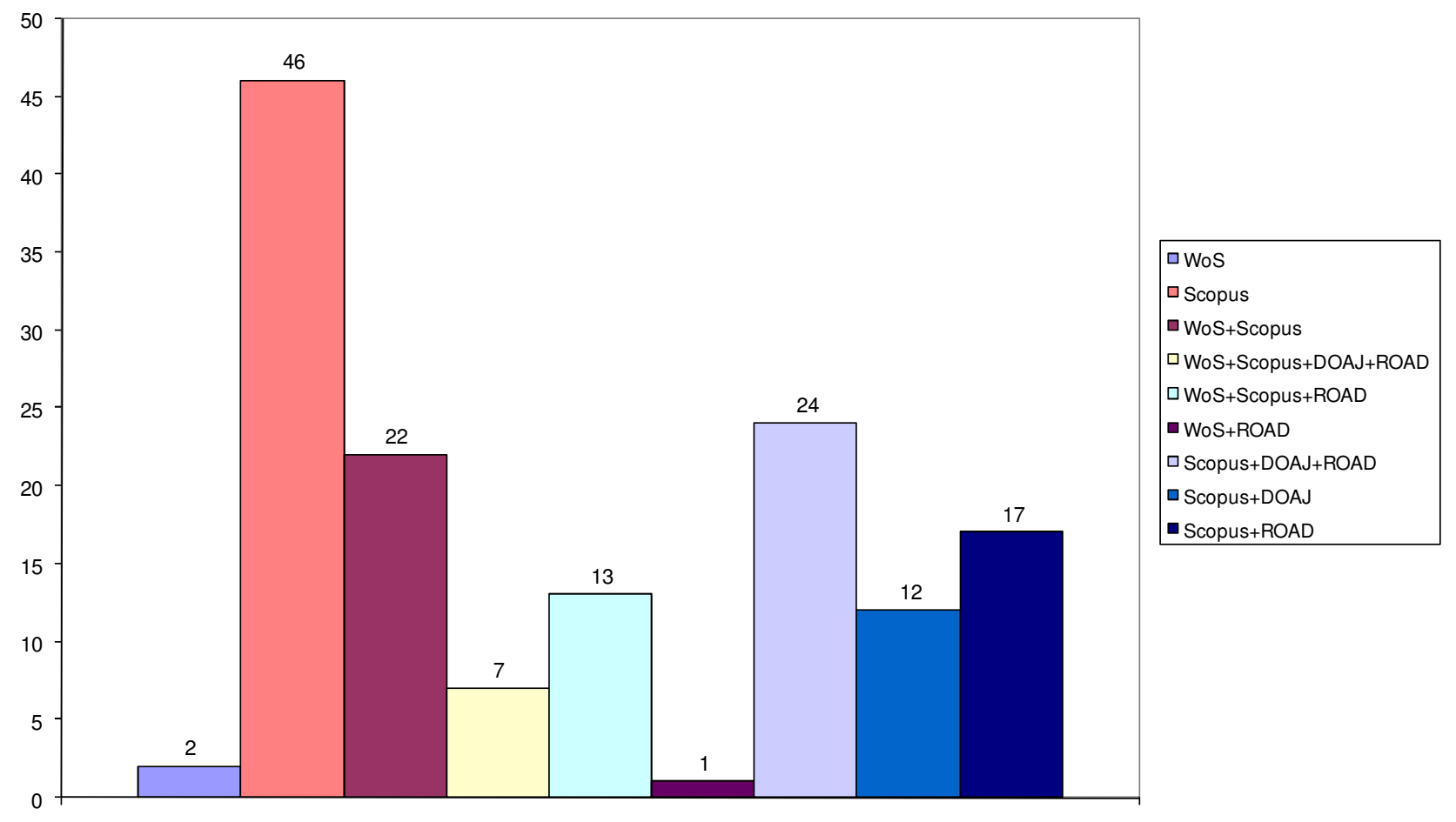

Figure 3. G2 journals indexed in one or more of the investigated databases

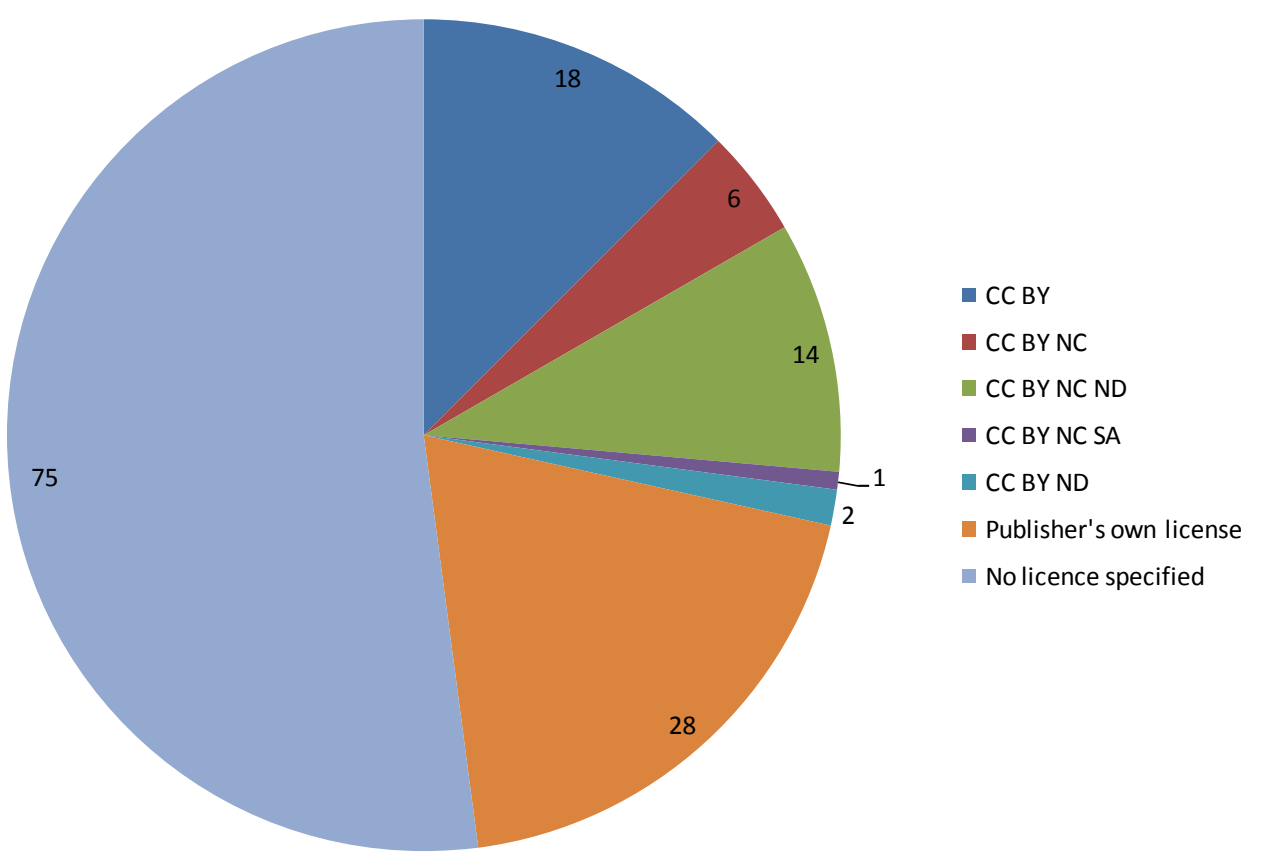

Figure 4. Type of O.A. licences used by G2 journals 


\subsection{Publishing charges}

Only 22 journals from G2 - of which only two declare hybrid O.A. - require article fees, under different names: submission, processing or publication charges. This translates into about $15 \%$ of the Romanian top O.A. journals.

In the meantime, about $27 \%$ of DOAJ journals require APCs $(2,964$ out of 11,146$)$ (DOAJ 2018; numbers available at 6 April 2018).

The fees requested by G2 journals vary between 50 and 500 Euros, averaging at about 193 Euros and with a median of 150 Euros. Only three journals offer charge waivers.

There have been a number of different studies worldwide regarding the average APC with values generally orbiting around 2,000 Euros. The JISC study from 2016, for example, found the average APC at 1,745 pounds for 2014-2015 (about 1,998 Euros) and the mean APC at 1,680 pounds or about 1,924 Euros (JISC 2016). Romanian fees average around $10 \%$ of those found in the mentioned study.

\subsection{Peer-review}

An important part of G2 journals (51 - 35\%) do not provide, on their websites, details regarding the type of peer-review they use. For the journals that provide this information, the most common are the double blind (50 journals) and blind (37 journals) peer-review. More flexible procedures open peer-review and optional blind peer-review (where the peer-reviewers can choose to disclose their identity or to remain anonymous) - are declared by only 6 journals (see Fig. 5)

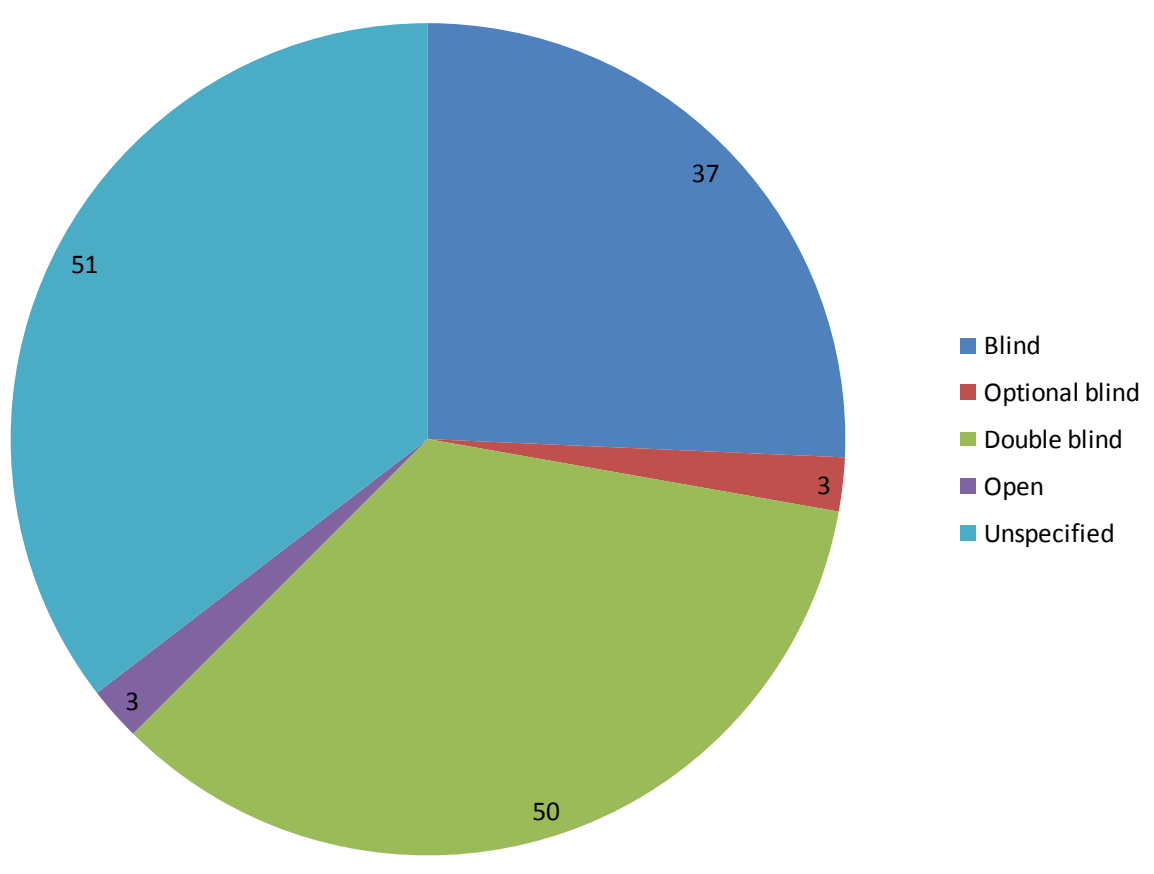

Figure 5. Type of peer-review declared by G2 journals 


\section{Discussion and conclusions}

This study offers, for the first time, an analysis of the way in which editors of Romanian scholarly journals relate to the O.A. movement. The analysis of the journals indexed in at least one of the two main bibliometric databases has shown that 144 of the 167 Romanian journals are O.A. As open access is not a hot topic in the Romanian scholarly environment, this high percentage (86\%) was quite unexpected. It indicates that O.A. is no longer a fringe of Romanian scholarly publishing but, at least for the top journals, the main type of publishing. It also shows willingness from Romanian editors to make their journals available to bigger audiences and an overall openness.

However, established O.A. repertories such as DOAJ and ROAD do not properly cover top Romanian O.A. journals (48\% of O.A. journals are not present in either). This hurts their visibility and suggests that, for Romania, DOAJ and ROAD are not effective tools for mapping O.A. publishing. It may also indicate that Romanian editors either don't consider indexing in DOAJ and ROAD necessary or ignore this opportunity. We can speculate that, considering the fact that WoS indexing is considered the highest level in the Romanian academic evaluation system, DOAJ indexing might not present any clear benefits. The small percentage of ROAD indexing (not depending on the editor) can be explained by the lack of overall O.A. information on the editors websites - which makes indexing by a third-party more difficult.

A significant part of the analysed journals do not offer information regarding the open access policies and licenses, although they offer free access to articles (Bronze O.A.). The predominance of Bronze O.A. could be interpreted as a poor knowledge of the O.A. tools and policies: the publishers are willing to provide unrestricted access to the content of the journals, but don't know how or are not interested in putting this policy in connection with the O.A. movement. Considering that in Romania the commercial potential of this kind of journals is rather low and consequently the main objective of providing free access is the increase in visibility, we believe that the apprehension usually invoked in respect to Bronze O.A. (the fact that the lack of O.A. licence indicates the possibility that the editors will go back to paid access) is highly unlikely to occur.

The fact that the percentages of journals in our study which require APCs are significantly lower than worldwide ones (15\% vs $27 \%$ ) may indicate that Romanian top O.A. journals are seen by their editors less as a self-sustaining or even profitable business and more as an activity that needs to be sustained by external means. The small number of journals which require APCs and the low value of these APCs, compared with the worldwide average, also reinforces the impression that Romanian O.A. journals are not seen by their editors as businesses.

The websites of O.A. journals vary in quality with an important part being substandard and lacking essential information, like the type of peer review used. This shows a certain lack of professionalism in scholarly publishing, in contrast with the quality of these journals, validated through indexing in the most important bibliometric databases.

We consider that our study facilitates future bibliometric analysis of Romanian O.A. journals. The small size of the O.A. publishing market and the fact that a significant number of Romanian journals do not provide details regarding their policies or editorial practices, although they might in the future, makes the figures presented in this study susceptible to important changes on short and medium term.

\section{Note}

1. The results of this study have been presented at the The 9th International Conference on Information Science and Information Literacy, Sibiu, Romania (April 19-20, 2018). 


\section{References}

ALLEA - All European Academies (2012) Open Science for the 21st century : A declaration of ALL European Academies, available: http://bit.ly/rrbsi42018a [accessed 26 February 2019].

Clarivate Analytics (2018) Master Journal List, available: http://mjl.clarivate.com [accessed 30 March 2018].

Directory of Open Access Journals (DOAJ), available: https://doaj.org/ [accessed 30 March 2018].

Directory of Open Access Scholarly Resources (ROAD), available: http://road.issn.org/en/ contenu/purposes-road-project\#.Wr40Qpe-nIU [accessed 30 March 2018].

Florian, R. and Florian, N. (2006) Majoritatea revistelor ştiinţifice româneşti nu servesc ştiinţa [The majority of Romanian scientific journals do not serve science], Ad Astra 5(2), pp. 1-26, available: http://www.ad-astra.ro/journal/9/florian_reviste_locale.pdf [accessed 26 February 2019].

Gargouri, Y., Larivière, V., Gingras, Y., Carr, L. and Harnad, S. (2012) Green and Gold Open Access Percentages and Growth, by Discipline, $A R X I V$, June 16, available: http://arxiv.org/ abs/1206.3664 [accessed 18 February 2019].

Guvernul României (2018) Parteneriatul pentru Guvernare Deschisă : Planul Național de Acțiune 2018-2020 [Partnership for Open Government : the National Action Plan 2018-2020], available: http://bit.ly/rrbsi42018b [accessed 18 February 2019]

Guvernul României (2014) Hotărâre nr. 929 din 21 octombrie 2014 privind aprobarea Strategiei naţionale de cercetare, dezvoltare şi inovare 2014-2020 [Decision no. 929 from October, 21, 2014 regarding the approval of the National Strategy for Research, Development and Innovation 20142020], available: http://bit.ly/rrbsi42018c [accessed 18 February 2019].

ISSN-INTERNATIONAL CENTRE (2017?) ROAD, the Directory of Open Access scholarly Resources, available: https://www.issn.org/services/online-services/road-the-directory-of-openaccess-scholarly-resources/ [accessed 18 February 2019].

Laakso, M. and Björk, B.C. (2016) Hybrid open access - A longitudinal study, Journal of Informetrics, 10(4), pp. 919-932, available: http://dx.doi.org/10.1016/j.joi.2016.08.002 [accessed 18 February 2019].

Laakso, M., Björk, B.C. (2012) Anatomy of open access publishing: a study of longitudinal development and internal structure, BMC Medicine, 10(1), pp. 124-132, available: https:// doi.org/10.1186/1741-7015-10-124 [accessed 18 February 2019].

Landoy, A. et al. (2016) Open Access policies and experiences in Norway, Romania and Moldova, Qualitative \& Quantitative Methods in Libraries, pp. 643-651, available: http://bit.ly/rrbsi42018d [accessed 18 February 2019].

Piwowarl, H. et al. (2018) The state of OA: a large-scale analysis of the prevalence and impact of Open Access articles, PeerJ, February 13, 2018, available: https://peerj.com/articles/4375/ [accessed 15 February 2019].

UEFISCDI (2017) Reviste românești indexate/cotate "ISI": reviste incluse în Science Citation Index Expanded (SCI-EXPANDED), Social Sciences Citation Index (SSCI) sau Arts and Humanities Citation Index (AHCI) ["ISI" indexed/rated Romanian journals: journals included in the Science Citation Index Expanded (SCI-EXPANDED), Social Sciences Citation Index (SSCI) sau Arts and Humanities Citation Index (AHCI)], available: http://bit.ly/rrbsi42018e [accessed 30 March 2018].

Samash, Katie (2016) Article processing charges (APCs) and subscriptions: Monitoring open access costs, JISC, available: https://www.jisc.ac.uk/sites/default/files/apc-and-subscriptions- 
report.pdf [accessed 14 February 2019].

Scopus preview: Scopus, available: http://bit.ly/rrbsi42018f [accessed 30 March 2018].

Solomon, D. J. and Björk, B. (2012) A study of open access journals using article processing charges, Journal of the Association for Information Science and Technology, 63(8), pp. 14851495, available: https://doi.org/10.1002/asi.22673 [accessed 18 February 2019]. 